\title{
Ports, external costs and Northern Italian transport network design: effects for the planned transformation
}

\author{
Ambrosino Daniela ${ }^{a}$, Ferrari Claudio ${ }^{a}$, Sciomachen Anna ${ }^{a}$, Tei Alessio ${ }^{b 1}$ \\ ${ }^{a}$ Department of Economics, University of Genoa, Italy \\ ${ }^{b}$ School of Marine Science and Technology, Newcastle University, United Kingdom
}

\begin{abstract}
Modern ports need to be inserted in an efficient network in order to exploit all their potential, positively affecting both the efficiency of the local markets and the external costs of the served industries. Moreover, the role of the ports within the whole supply chain is affected by the location and the organization of intermediate facilities - such as logistics parks or inland ports - that heavily influence both the effectiveness of the logistics corridors and the externalities generated by the transport industry. New and adequate infrastructures can then reduce congestions, pollution, and accidents smoothing the whole logistics chains. The proposed study aims at discussing the effects in terms of rail share of the different planned interventions that are aimed at increasing the rail capacity of the network under investigation. In order to achieve this goal, a network optimization model has been solved by the optimizer solver of a spreadsheet. Outcomes can be used in order to improve current transport policies that might foster a more efficient and less impacting hinterland transport solution.
\end{abstract}

Keywords: External costs, Network Optimization; Cost Internalization, netwrok development, internalization policy

* Corresponding author. Mail. Alessio.tei@ncl.ac.uk 


\section{Introduction}

Modern transport systems rely on complex integrated networks that are based on a variety of services and infrastructures. Thus, global supply chains and logistics corridors are based on the degree of connectivity between points distributed worldwide and they rely on the efficient and seamless transport flow along the whole network (e.g. Schwarze and Voss, 2015). This framework involves a plurality of actors and transport nodes that assure the needed connection between globalised origins and destinations (e.g. Meersman et al., 2009). For this reason, all possible transport alternatives connecting a port to its own hinterland represent strategic logistics solutions able to foster the port competitiveness and its role within the international transport network (e.g. Al Enezy et al., 2016; Ferrari et al., 2011; Tongzon, 2009). Concerning this issue, several contributions highlighted how the organisation of intermodal transport - that efficiently uses either inland ports (e.g. intermodal terminals for cargo storage and the transhipment of freight) or logistics parks (e.g. inland ports offering added value services and logistics operations to the cargo) - might enlarge port catchment areas (e.g. Vermeiren and Macharis, 2016; Van Den Berg and De Langen, 2011; Notteboom and Rodrigue, 2008), influencing the establishment of new served regions. Moreover, the terminal facilities shape the port hinterland and contribute to spread the benefits that hosting a port can guarantee to wider regions (e.g. Yang et al., 2016, Bottasso et al., 2014).

Therefore, the quality of connectivity between ports and their hinterlands is not only important for efficiency reasons - or for spreading the benefits generated by a transport infrastructure - but also for taking into account the different costs paid by local communities due to different transport mode alternatives for reaching the port (inside each province). For instance, transport generates not only direct private costs but also social costs (i.e. pollution, congestion, and noise) due to the potential negative externalities (e.g. lannone, 2012; Arnold et al., 2004). In the maritime academic literature external costs have been studied since the '90s (e.g. Lakshmanan 2001; Meersman et al., 1998); in particular - as happened also for other transport modes - many studies tried to evaluate the gap existing between the private perceived costs of a specific transport mean and its actual cost for the society (as defined by Pigou, 1932). Estimations varied over time due to the difficulties in clearly evaluating external factors generated by a given transport system and their range of impact: the "Handbook on estimation of external costs for the transport sector" (Maibach et al., 2008) constituted one of the first attempt to systematize external costs evaluating and comparing them over large regions (i.e. EU). This "Handbook" is regularly updated and it represents a milestone in the monetary estimation of external costs. Furthermore, the values represented in Maibach et al. (2008) represent an alternative to the evaluations studied under other EU projects that aim at assuring their internalization (e.g. eurovignette). 
While recent literature focused its discussion on effective flow distribution in a specific hinterland (e.g. Notteboom and Rodrigue, 2008; Van der Horst and van der Lugt, 2011; Ambrosino and Sciomachen, 2016) or on the benefits of the internalization of transport costs (e.g. Grosso, 2011), at the best of our knowledge relatively few studies focus on external costs in order to optimize intermodal transport paths (e.g. Janic, 2007; Arnold et al., 2004; lannone, 2012) or on the possibility to introduce greener solution thanks to an effective intermodal transport (e.g. Lidstad et al., 2016; Eng-Larsson and Kohn, 2012; Sambracos and Maniati, 2012). Nevertheless, as stated by Mostert and Limbourg (2016) the use of external costs as a competitive factor for freight transport is a key issue for the future of transport industry, increasing the performance of the intermodal transport (Mostert et al., 2017). A recent work written by Ambrosino et al. (2016) applied a Mixed Integer Linear Programming (MILP) model in order to evaluate the optimal distribution of containerized imports in Northern Italy, in case of companies would consider both private and external costs in their objective function. The authors analysed the impact that different types of external costs included in the decision process could have on both the cargo flows modal split and the location decisions. The inclusion of these costs in the decision process showed how rail transport would increase its competitiveness and how the lack of physical investment in additional rail infrastructure is affecting to realization of such a scenario, even more than the simple consideration of external costs.

Starting from these results, the current paper tries to understand if current regional plans for the future of rail transport (e.g. already planned investments), together with the application of specific incentives, might improve the current situation.

In order to do so, a MILP model derived from that proposed in Ambrosino et al. (2016) has been applied in order to determine what of the future investment plans are able to improve the transportation system; moreover, the model has also been used to understand how common policy tools can foster an improvement of the presented results. Thus, current paper studies a real case scenario that is based on the North Italian regions, using the data included in Ambrosino et al. (2016). Since, as already said, the optimal solution of the paper was limited by current infrastructure limitations (namely the rail capacity constraints), this latter situation is tested against already funded projects that are planned to be operational within the next decade (as reported by the Consulta Nazionale per l'Autotrasporto e la Logistica, 2011). Data flows are based on information provided by Italian National Custom Agency for Ligurian ports (i.e. Genoa, La Spezia and Savona). Moreover, infrastructural data source are provided through public information published by the network managers. The base scenario describes the existing highway and railway network while three further scenarios are characterised by the planning improvements of the rail connection in Genoa (s.c. High Speed/High Capacity connection with the Po Valley), Savona and La Spezia (for both ports an improvement in the rail network is planned).

The paper is structured as follows. After this introduction, Section 2 focuses on the regional and port characteristics, while Section 3 is dedicated to the description of the network model applied to the Northern Italian case study. Section 4 discusses the results of the analysis and Section 5 addresses conclusions and insights for future research developments.

Regional framework

Freight distribution in Italy is mainly based on an extensive use of the road transport and this mode is also dominant for the volume of cargo generated by the domestic seaports (e.g. Consulta Nazionale 
per l'Autotrasporto e la Logistica, 2011). The statistics produced by the European Environmental Agency (EEA, 2015; 2010) - as well as other several academic papers and reports (e.g. lannone, 2012; Consulta Nazionale per l'Autotrasporto e la Logistica, 2011) - highlight how the unbalanced modal split is deeply impacting on the environment given that road transportation produces the worse external effects. This issue has been deeply analyzed and several projects have dealt with the externalities generated by trucks (e.g. De Martino et al., 2013). While modal shift policies are often based on incentives to make modal alternatives more convenient - as for the promotion of Short Sea Shipping (e.g. Ferrari and Tei, 2012) - less attention has been paid on policies able to internalize external costs. This issue is mainly linked to the poor political consensus given by these latter policies and by the fact that they are harder to apply. Nevertheless, rational use of the most efficient transport solution considering the overall generated costs - is essential in order to minimize the overall generalized transport costs.

Concerning the cost internalization, in accordance with traditional economic literature (e.g. Pigou, 1932) and policy reports (e.g. Maibach et al., 2008), road transport would become much more expensive in comparison to rail transport, if external costs would be added to the private ones. Among the main external costs, the "Handbook on estimation of external costs in the transport sector" (Maibach et al., 2008) took into consideration three main components, namely: pollution (atmospheric and noise emissions), risk and congestion. Other specific external costs have been also considered in the handbook but not all of them can be easily adapted to all different European contexts or transport solutions, as for the climate change effects.

As already mentioned, external costs are not only related to environmental aspects but also to some side effects that can have a great impact also on the network efficiency, such as congestion that can heavily affect the efficiency of the transport system. For this reason Janic (2007) and Mostert and Limbourg (2016) suggested that internalization process could positively impact on the rationalization of the flows. Incentives to promote the use of intermodality then could generate not only operational benefits but also social ones.

\section{The collected data}

As introduced above, the aim of this paper is to provide an evaluation of the effects of the planned investments on the possibility to shift some traffic from road to rail, thus reducing the external cost of road transport. In order to achieve this goal, current North Italian transport system has been modelled using public information, while - in order to compare the discussed solutions with those included in Ambrosino et al. (2016) - port data flows used are the same of the cited paper, i.e. Customs official data for the containerized import.

In this picture Ligurian ports accounted in $\mathbf{2 0 1 5}$ for more than 35\% of the Italian container traffic being the greatest gateway port region in Italy - and for about $18 \%$ of the overall Italian port throughput (Assoporti, 2016). The ports of Genoa and La Spezia are the second and third container ports in Italy, respectively. Moreover, Genoa is the biggest Italian gateway and in the last year registered an increase of container movements (around 2.2 million TEU in 2015), making the port close to the first position of the ranking. On the other hand, starting from the end of the '00s the port of Savona reduced its share in the container traffic due to the crisis of its reefer terminal, now accounting for about 90,000 TEU per year. Despite this, the current development of a new APMT terminal will expand the capacity of nearly 600,000 TEU per year before the 2020 (making the port of Savona, 
potentially, the fourth container gateway port in Italy). Furthermore, the new Italian port law (law decree n. 169/2016) has recently merged the port of Genoa and Savona, creating the biggest port in Italy for many traffic categories, generating further challenges in the port planning and for their hinterland connections (Parola et al., 2016).

The port hinterlands for the studied cases present several overlaps even if specific trade patterns differentiate part of the areas served by the three ports. Table 1 describes in which NUTS-3 regions port traffic is more concentrated.

Table 1 - Port freight distribution (main import destinations; NUTS3 level)

\begin{tabular}{ccc|cc|cc}
\multicolumn{2}{c}{ Rank } & \multicolumn{2}{c}{ Genoa } & \multicolumn{2}{c}{ La Spezia } & \multicolumn{2}{c}{ Savona } \\
\cline { 2 - 7 } 1 & NUTS3 & $\%$ & NUTS3 & $\%$ & NUTS3 & $\%$ \\
2 & Milan & $21,7 \%$ & Milan & $15,8 \%$ & Torino & $25,7 \%$ \\
3 & Pavia & $20,7 \%$ & Rome & $6,2 \%$ & Milano & $15,2 \%$ \\
4 & Turin & $8,3 \%$ & Bologna & $5,6 \%$ & Genova & $9,3 \%$ \\
5 & Bergamo & $3,7 \%$ & Modena & $5,0 \%$ & Varese & $9,1 \%$ \\
6 & Rome & $3,3 \%$ & Reggio Emilia & $4,5 \%$ & Ravenna & $6,2 \%$ \\
7 & Brescia & $3,1 \%$ & Vicenza & $4,2 \%$ & Rome & $4,1 \%$ \\
8 & Piacenza & $3,0 \%$ & Firenze & $3,9 \%$ & Cuneo & $3,6 \%$ \\
9 & Cuneo & $2,7 \%$ & Verona & $3,8 \%$ & Bergamo & $2,3 \%$ \\
10 & Varese & $2,6 \%$ & Brescia & $3,5 \%$ & Pavia & $2,2 \%$ \\
& Como & $2,0 \%$ & Bergamo & $3,3 \%$ & Reggio Emilia & $2,1 \%$ \\
& Others & $28,8 \%$ & Others & $44,2 \%$ & Others & $20,2 \%$
\end{tabular}

Source: Own elaboration from Customs Database, 2012.

Considering the spatial distribution of the containerized import handled by the three Ligurian ports (Table 1 shows main destinations, excluding the port province data), it is important to outline a substantial overlapping in the catchment areas between the ports of Savona and Genoa - basically corresponding to Piedmont (in particular Turin and Cuneo) and Lombardy (in particular Milan) regions, while La Spezia is more focused on the cargoes distributed to the Emilia-Romagna region. Despite the geographical concentration of some of the traffic, another peculiarity of the considered ports is the wide range of the catchment areas. For instance, the smallest studied container port (i.e. Savona) attracts cargos from the Venice region despite the presence of local and closer ports, such as Venice, Ravenna and Trieste.

All the Ligurian three ports have several plans to expand their container activities thanks to different infrastructural projects. For instance, the already mentioned APM terminal in Savona or the enlargement of two container terminals in Genoa that should guarantee an additional capacity of more than 300,000 TEU by 2020 . At the same time, local authorities and national government plan to expand the network of infrastructures surrounding the ports, mainly focusing in adding new railway capacity. The biggest investment is the so-called "Terzo Valico", a new high-speed and high-capacity rail link that will shorten the path between Genoa and the Po Valley, adding capacity in the connections between the main Ligurian port and both Turin and Milan. 
As said, the strict majority of the flows are currently delivered by road (on average the three ports move by rail about $10 \%$ of their throughput, even if they are registering a growing trend). Several plans may be found in the port websites discussing the possibility to use some inland ports in order to serve different markets or to enlarge the share of port traffic moving by railway. Figure 1 shows the location of the three ports in respect to the Northern Italy. Moreover, main transport nodes - as described in the following section - as well the current railway and motorway networks are represented.

Figure 1: Maps of the Italian network

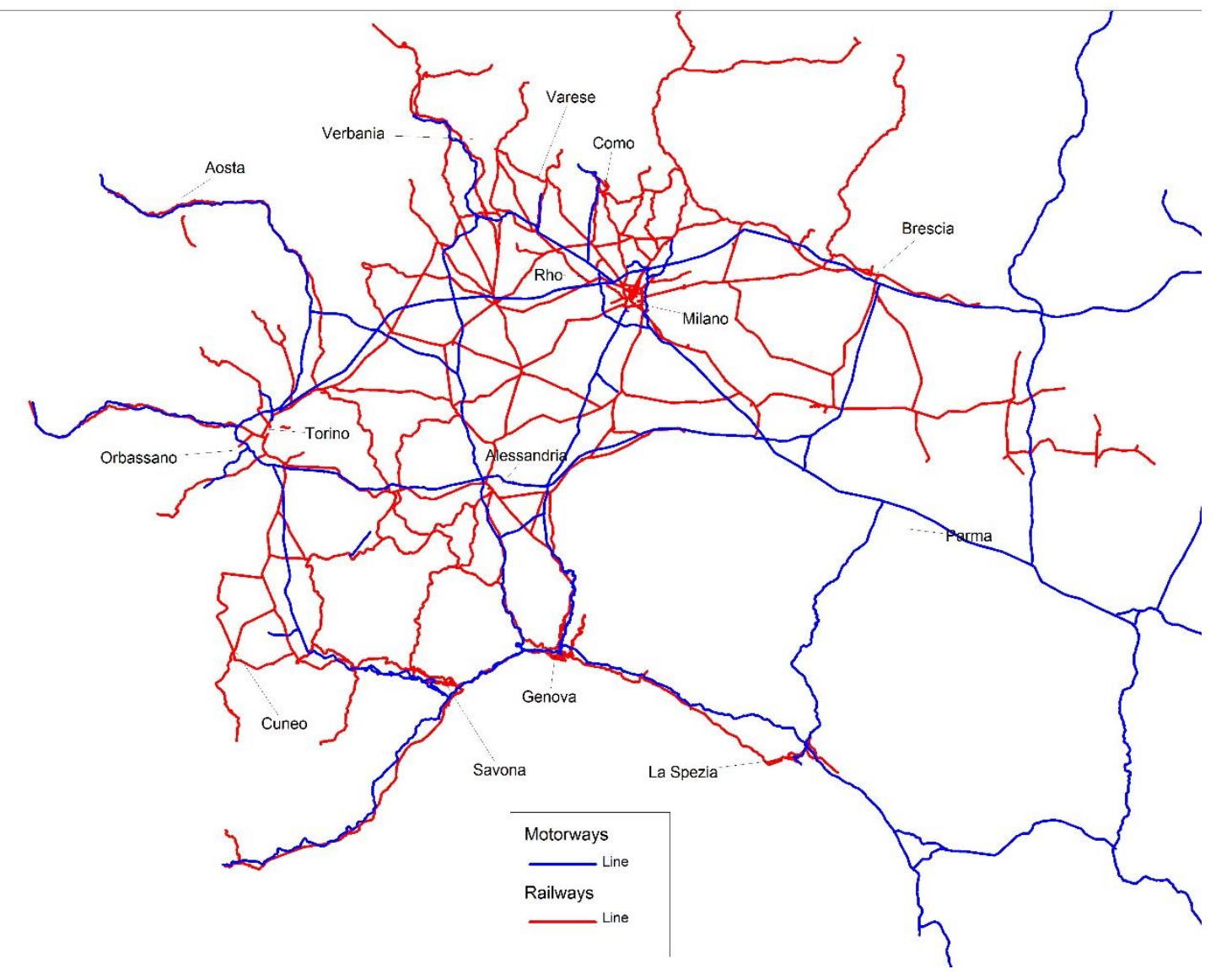

Considering the network data about infrastructural constraints and distances, official collected statistics show the limitations of the current network. Published databases include the Ligurian Region Logistics Plan (s.c. Regional Logistics Plan) and the infrastructure manager reports (i.e. Rete Ferroviaria Italiana for railways and Autostrade per I'Italia for the motorways, respectively). Thus, considering the collected data, the two transport mode networks have been built: as underlined by the Regional Logistics Plan (Regione Liguria, 2010), the main hinterland connections are represented by four main inter-regional links (Genoa-Milan/Turin; Savona-Turin; La Spezia-Parma; La Spezia-Leghorn) and an intra-regional one (Ventimiglia-La Spezia) that allow to easily reach the main destinations using both motorways and railways. Motorway and railway networks use similar origin-destination trajectories but rail lines (e.g. La Spezia-Parma and Genoa-Milan) are characterized by several technical constraints that are currently increasing the costs of moving freight by rail. In particular, the constraints are related to the slope of the rail tunnels, mainly in the two branches connecting Genoa with Piedmont, the presence of only one track in mix freight/pax rail branch, in both Savona and La Spezia inter- 
regional links, and the tunnel size. These limitations affect the costs of the rail operations in three ways: reducing the length of the trains and then their capacity; increasing the number of locomotives needed to overcome steepest rail trunk and reducing the speed of trains thus diminishing the number of possible daily trains together with the time schedule. For instance, only concerning the Ligurian rail network, the maximum number of daily trains varies from a minimum of 60 to a maximum of 180 trains-day per track (to be shared in passengers and freight trains). In order to overcome these limitations, some improvements have been planned, the high speed/high capacity link will allow for longer trains and it will add new capacity (until 30 TEUs more for each train), while new rail terminals in Savona and La Spezia will allow to form a higher number of trains per day (until 10 trains more per day).

On the other hand, the motorways do not present similar constraints, even if bottlenecks are quite frequent on the highways too, with the number of lanes that varies depending on the specific highway (and impacting on the overall capacity).

Moreover, in all the three ports part of the freight truck movements are made within the city center area, affecting also the urban congestion level. Eventually, because the current intra-regional motorway connection passes through the Genoa city center - and it also functions as urban ring road - the trucks passage also affects the city pollution even if they are not directly handled in the port terminals located within the city center. Concerning market organization, road transport is quite competitive with several companies assuring the truck services while rail market is much less competitive with a few operators that can access the network. Moreover, rail services within the ports are managed by a single operator, given safety and security issues.

As far as the costs are considered, several studies have been used in order to find the main cost components.

For the private cost component, official documentation has been used (i.e. Italian Ministry of Transport), mainly for establishing an official minimum cost for the road transport for the year 2011 (data used in the model) thus deriving an average value of about 1.6 euro for TEU/Km varying with respect to the distance covered from about $1.3 € / \mathrm{km}$ to about $1.9 € / \mathrm{km}$ (Italian Ministry of Transport, 2011). Similar official data related to the rail network costs are not published but estimations on the future cost access to the infrastructure can be found on the rail manager website (e.g. Rete Ferroviaria Italiana, 2016). Moreover, as discussed in the literature (e.g. Baumgartner, 2001; Grosso, 2011), different cost estimations can be developed for the rail transport. In order to guarantee the comparison with the results made by Ambrosino et al. (2016), the same costs are applied. Thus, an average value of about 1.96 euro TEU/Km, but with high variations depending on constraints and distances (costs are actually estimated, in the model, using the vehicle as unit of measure). Since current estimation of access cost, the high speed/high capacity link registers a cost of about $20 \%$ more than usual rail solution.

\section{A weighted graph representing the multimodal network}

The analysis on the import flows of the multimodal network described in the previous sections has been carried out using a weighted graph representing the nodes of the network and the existing road and railway connections. More formally, let be $G=(V, E)$ the weighted graph, with $V$ the set of $n$ nodes, given by the union of four subsets of nodes, representing, respectively, the existing inland ports $\left(V_{H}\right)$, the seaports $\left(V_{O}\right)$, that are the origin nodes of the flows, the destination nodes $\left(V_{D}\right)$, i.e. the demand 
nodes of the network, and the transition nodes $\left(\mathrm{V}_{\mathrm{T}}\right)$; and $\mathrm{E}$ the set of $m$ oriented arcs, given by the union of two subsets of arcs representing the road $\left(E_{T}\right)$ and railway $\left(E_{W}\right)$ connections between nodes of $\mathrm{V}$. Each arc of $\mathrm{E}$ is characterized by a given capacity, expressed as the maximum flow that can pass through it, a transportation cost that is function of the travelled distance and an external cost given by the sum of the noise and pollution cost components.

An example of graph $\mathrm{G}$ is sketched in Figure 2, where black lines represent the road arcs and dashed ones the rail connections.

Figure 2: Example of graph $\mathrm{G}$

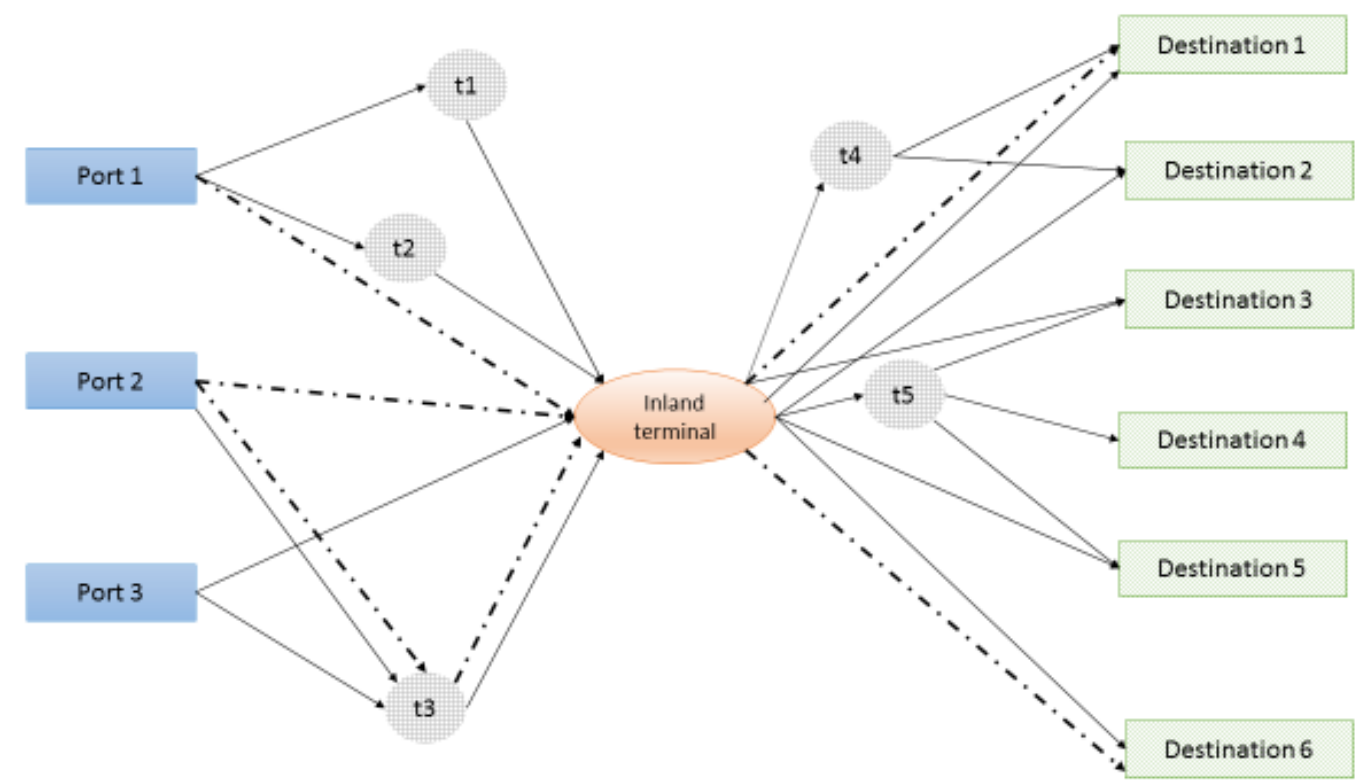

Some nodes of the network have other specific characteristics. Each origin node $\left(V_{0}\right)$ is characterized by an outflow limitation per mode and a congestion cost used for representing the congestion caused by the flow of trucks leaving the seaports and thus function of the distance travelled by trucks for leaving the port and connecting them to the highway. Each inland port $\left(\mathrm{V}_{\mathrm{H}}\right)$ has many limitations due to the handling capacity, the in/out flow capacity for each transport modality, and some operative and fixed costs that depend on both their size and their handling capacity. Note that no limitations are related to transition nodes that are necessary for representing in more details the network and also for computing in a correct way the flows on arcs.

By using this network model it is possible to solve a flow optimization problem and determine both the mode of transport and the paths to use for shipping the required volume of goods from the origin nodes $\left(V_{0}\right)$ to the destination ones $\left(V_{D}\right)$.

The optimal network obtained in Ambrosino et al. (2016), together with the existing transportation network are now investigated in such a way to determine what interventions are able to improve the transportation networks (i.e. the existing and the optimal ones here denoted $\mathrm{CN}$ and $\mathrm{ON}$ ) and their costs.

In this work the main aim is to determine and compare the optimal flows (in terms of both paths and modal split) in different scenarios corresponding to the current network (CN) and the optimal one (ON) with different combinations of the available interventions that are summarized in Table 2.

Table 2: possible interventions on the network 


\begin{tabular}{|c|c|c|c|}
\hline Intervention & Description & Main Characteristics & Acronym \\
\hline High Speed Link & $\begin{array}{c}\text { A new network with new } \\
\text { high speed and high } \\
\text { capacity rail links }\end{array}$ & $\begin{array}{c}\text { Introduction of higher } \\
\text { rail capacity on the main } \\
\text { port-hinterland link }\end{array}$ & 11 \\
\hline $\begin{array}{c}\text { New rail park in a minor } \\
\text { node }\end{array}$ & $\begin{array}{c}\text { A new network with } \\
\text { improvement of the rail } \\
\text { terminal planned for the } \\
\text { port of Savona }\end{array}$ & Increasing node capacity \\
\hline $\begin{array}{c}\text { New rail park in the } \\
\text { second biggest node }\end{array}$ & $\begin{array}{c}\text { A new network with } \\
\text { improvement of the rail } \\
\text { terminal planned for the } \\
\text { port of La Spezia }\end{array}$ & Increasing node capacity & 13 \\
\hline
\end{tabular}


The planned improvements are modeled in the graph thanks to:

- new connections for including the new rail links in case of $\mathbf{I 1}$.

- higher rail capacity for the outflow at the origin nodes (i.e. port of Genova in case of I1, Savona and La Spezia respectively in case of 12 and 13 );

The size of the graphs representing the above described network is the following: $\left|V_{0}\right|=3,\left|V_{D}\right|=13$, $\left|V_{T}\right|=34,\left|V_{H}\right|=1$ in $O N$ and 0 in $C N ;\left|E_{T}\right|=85$ and $\left|E_{W}\right|=73$ (=75 when 11 is considered).

For each scenario the optimal paths to transfer goods from the origin nodes to the destination ones are determined as described in the next section.

\section{Using a spreadsheet for optimizing the flows in the network}

The input data of the network are reported in a spreadsheet (i.e. arcs, nodes, their capacities, their costs and so on) and, through the solver of the spreadsheet, the flows on the arcs of the network are defined in order to minimize the logistic costs and respect all the capacity limitations on both arcs and nodes. Logistic costs are given by transportation costs, external costs and handling ones.

For defining in a correct way the flows on the arcs of the network, for each node it is necessary to compute (as in Figure 3):

- the inflow by both road and rail modality;

- the total inflow computed as the sum of the road and rail flows;

- the outflow by both road and rail modality;

- the total outflow computed as the sum of the road and rail flows;

- the net flow given by the difference between the total inflow and the total outflow.

The flow decisions must be taken in order to guarantee that:

1. the transport demand is satisfied: the net flow must be equal to the demand for each destination node and the offer for each seaport (see red data in Fig. 3). For the transition nodes the demand is equal to zero, implying that the flow entering into a transition node must then leave it (see green data in Fig. 3);

2. the flow conservation for each transport mode in each transition node is respected: the inflow by the road [rail] modality must be equal to the road [rail] outflow (see blue data in Fig. 3);

3. the flow conservation at each inland port is respected: in this case the flow conservation is not for each modality but regards the total flow reaching and leaving the inland port. Note that in each inland port node it is possible to change the transport mode, thus for an inland port node the total inflow must be equal to the total outflow (see yellow data in Fig. 3);

4. the handling capacity of each inland port is respected: for each inland port the total inflow must be lower than (or equal) the handling operative capacity;

5. the in/out flow capacity for each mode of transport of each inland port is respected;

6. the rail out flow capacity of origin nodes is respected.

The flow decisions must be taken in order to minimize:

a. road and rail transportation costs: given for each arc of the network, the total transportation cost is computed as unit transport cost of the arc multiplied for the flow passing through the arc (then summarizing for all the arcs of the network); 
b. handling costs: given for each inland terminal, the total handling cost is computed as unit handling cost multiplied for the total flow managed by the inland terminal (then summarizing for all the inland terminals);

c. congestion costs: given for each seaport, the total congestion cost is computed as unit congestion cost multiplied for the rail outflow of the seaport (then summarizing for all the seaports);

d. pollution and noise costs: given for each arc of the network, the total pollution ad noise cost is computed as unit cost of the arc multiplied for the flow passing through the arc (then summarizing for all the arcs of the network); 
Figure 3: Flow analysis in the network

\begin{tabular}{|c|c|c|c|c|c|c|c|c|c|c|}
\hline \multicolumn{11}{|c|}{ FLOW ANALYSIS E THE METWORK } \\
\hline modes & \begin{tabular}{|c|} 
Type \\
(portfinlandy \\
destinstiondt \\
ransiction)
\end{tabular} & $\begin{array}{l}\text { renow - } \\
\text { road } \\
\text { modalinty }\end{array}$ & $\underset{\text { modiality }}{\text { mow }}$ & $\begin{array}{l}\text { tolal } \\
\text { inlow } \\
\text { (road * } \\
\text { rail) }\end{array}$ & $\begin{array}{l}\text { ontilow - } \\
\text { moad } \\
\text { modality }\end{array}$ & $\begin{array}{c}\text { ontllow - rat } \\
\text { modarity }\end{array}$ & $\begin{array}{l}\text { total ontllow } \\
\text { (road * rail) }\end{array}$ & $\begin{array}{c}\text { net llow } \\
\text { (road * } \\
\text { rail) }\end{array}$ & & Dernand foller \\
\hline Alessandria & d & 0 & 3977 & 3977 & 0 & 0 & 0 & 3977 & $=$ & 3977 \\
\hline Aosta & d & 756 & 0 & 756 & 0 & 0 & 0 & 756 & $=$ & 756 \\
\hline Brescia & d & 114339 & 0 & 114338 & 0 & 0 & $\mathbf{0}$ & 114338 & $=$ & 114338 \\
\hline Como & d & 13759 & $\mathbf{0}$ & 13759 & $\mathbf{0}$ & $\mathbf{0}$ & $\mathbf{0}$ & 13759 & $=$ & 13759 \\
\hline Cuneo & d & 13575 & $\mathbf{0}$ & 135875 & $\mathbf{0}$ & $\mathbf{0}$ & 0 & 135875 & $=$ & 13575 \\
\hline Genova & d & 741 & 13167 & 13918 & 0 & 0 & 0 & 139018 & $=$ & 139.18 \\
\hline LaSpezia & d & 41081 & 1373 & 42454 & 0 & 0 & 0 & 42454 & $=$ & 42454 \\
\hline Milano & d & 116325 & 0 & 116325 & 0 & 0 & 0 & 116325 & $=$ & 116325 \\
\hline Parma & d & 53995 & $\mathbf{0}$ & 53995 & 0 & 0 & 0 & 53995 & $=$ & 53995 \\
\hline Savona & d & 0 & 3136 & 3136 & 0 & 0 & 0 & 3136 & $=$ & 3136 \\
\hline Torino & d & 40130 & 0 & 40130 & 0 & 0 & 0 & 40130 & $=$ & 40130 \\
\hline Varese & d & 11505 & 0 & 11505 & 0 & 0 & 0 & 11505 & $=$ & 11505 \\
\hline Verbania & d & 0 & 15052 & 15052 & 0 & 0 & 0 & 150152 & $=$ & 15052 \\
\hline Alessandrialnterportc & i & 0 & 158019 & 158019 & 756 & 15052 & $158: 19$ & 0 & $=$ & 0 \\
\hline MilanoInterporto & i & 0 & 0 & 0 & 0 & 0 & 0 & 0 & $=$ & 0 \\
\hline Torinolnterporto & i & 0 & 0 & 0 & 0 & 0 & 0 & 0 & $=$ & $\mathbf{0}$ \\
\hline GenovaPorto & $\mathbf{p}$ & $\mathbf{0}$ & 0 & 0 & 237600 & 32953 & 270553 & -270553 & $=$ & -270553 \\
\hline LaSpeziaPorto & $\mathbf{p}$ & 0 & 0 & 0 & 159400 & 1373 & $1597 / 73$ & $-1597 / 3$ & $=$ & $-1597 / 73$ \\
\hline SavonaPorto & $\mathbf{p}$ & 0 & 0 & 0 & 9448 & 3136 & 12594 & -12594 & $=$ & -12594 \\
\hline Acquíterme & $\mathbf{t}$ & 0 & 0 & 0 & 0 & 0 & 0 & 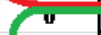 & - & 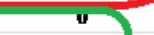 \\
\hline Arona & $\mathbf{t}$ & 0 & 15052 & 15052 & 0 & 15052 & 15052 & 0 & $=$ & 0 \\
\hline Arquata & $\mathbf{t}$ & 0 & 19786 & 19786 & 0 & 19785 & 19785 & 0 & $=$ & 0 \\
\hline Asti & $\mathbf{t}$ & 0 & 0 & 0 & 0 & 0 & 0 & 0 & $=$ & 0 \\
\hline Carrú & $\mathbf{t}$ & 53705 & 0 & 53705 & 53705 & 0 & 53705 & 0 & $=$ & 0 \\
\hline Chirasso & $\mathbf{t}$ & 0 & 0 & 0 & 0 & 0 & 0 & 0 & $=$ & 0 \\
\hline Cinisello & $\mathbf{t}$ & 0 & 0 & 0 & 0 & 0 & 0 & 0 & $=$ & 0 \\
\hline Fossano & $\mathbf{t}$ & 0 & 0 & 0 & 0 & 0 & 0 & 0 & $=$ & 0 \\
\hline Gallarale & $\mathbf{t}$ & 11505 & 0 & 11505 & 11505 & 0 & 11505 & 0 & $=$ & 0 \\
\hline GenowaTransito & $\mathbf{t}$ & 0 & 32953 & 32953 & 0 & 32953 & 32953 & 0 & $=$ & 0 \\
\hline Genouraloliri & $\mathbf{t}$ & 63324 & 0 & 63324 & 63324 & 0 & 63324 & 0 & $=$ & 0 \\
\hline hrea & $\mathbf{t}$ & 756 & 0 & 756 & 756 & 0 & 756 & 0 & $=$ & $\mathbf{0}$ \\
\hline LaSpexiaTransito & $\mathbf{t}$ & 159400 & 1373 & 159773 & 158400 & 1373 & $1597 / 73$ & 0 & $=$ & 0 \\
\hline Moncalieri & $\mathbf{t}$ & 40130 & 0 & 40130 & 40130 & 0 & 40130 & 0 & $=$ & 0 \\
\hline Monza & $\mathbf{t}$ & 0 & 0 & 0 & 0 & 0 & 0 & 0 & $=$ & 0 \\
\hline Mortara & $\mathbf{t}$ & 0 & 15052 & 15052 & 0 & 15052 & 15052 & 0 & $=$ & 0 \\
\hline Novara & $\mathbf{t}$ & 0 & 15052 & 15052 & 0 & 15052 & 15052 & 0 & $=$ & 0 \\
\hline Pania & $\mathbf{t}$ & 255927 & 0 & 255927 & 255927 & 0 & 255927 & 0 & $=$ & 0 \\
\hline Piacenza & $\mathbf{t}$ & $\mathbf{0}$ & $\mathbf{0}$ & 0 & 0 & $\mathbf{0}$ & 0 & 0 & $=$ & $\mathbf{0}$ \\
\hline Eho & $\mathbf{t}$ & 25264 & 0 & 25264 & 25264 & 0 & 25264 & 0 & $=$ & 0 \\
\hline Rivalla & $\mathbf{t}$ & 2559927 & 0 & 255927 & 255927 & 0 & 255927 & 0 & $=$ & 0 \\
\hline Rovrato & $\mathbf{t}$ & 0 & 0 & 0 & 0 & 0 & 0 & 0 & $=$ & 0 \\
\hline Romano & $\mathbf{t}$ & 255927 & 0 & 255927 & 255927 & 0 & 255927 & 0 & $=$ & 0 \\
\hline SanGiuseppe & $\mathbf{t}$ & 0 & 0 & 0 & 0 & 0 & 0 & 0 & $=$ & 0 \\
\hline Santhè & $\mathbf{t}$ & 756 & 0 & 756 & 756 & 0 & 756 & 0 & $=$ & 0 \\
\hline SaronaTransito & $\mathbf{t}$ & 53705 & 3135 & 56841 & 53705 & 3136 & 56841 & 0 & $=$ & 0 \\
\hline Segrate & $\mathbf{t}$ & 114398 & 0 & 114398 & 114378 & 0 & 114378 & 0 & $=$ & $\mathbf{0}$ \\
\hline Settimodulanese & $\mathbf{t}$ & 25264 & 0 & 25264 & 25264 & 0 & 25264 & 0 & $=$ & 0 \\
\hline Tortoma & $\mathbf{t}$ & 255927 & 0 & 255927 & 255927 & 0 & 2559927 & 0 & $=$ & 0 \\
\hline Troffarello & $\mathbf{t}$ & 0 & 0 & 0 & 0 & 0 & 0 & 0 & $=$ & 0 \\
\hline Valenza & $\mathbf{t}$ & 0 & 15052 & 15052 & 0 & 15052 & 15052 & 0 & $=$ & 0 \\
\hline Verumo & $\mathbf{t}$ & 0 & 0 & 0 & 0 & 0 & 0 & 0 & $=$ & 0 \\
\hline Vicolumgo & $\mathbf{t}$ & 0 & 0 & 0 & 0 & 0 & 0 & 0 & $=$ & 0 \\
\hline Vophera & t & 0 & n & 0 & 0 & 0 & 0 & 0 & $=$ & 0 \\
\hline
\end{tabular}

Table 3 shows the data used in the model and their impact on the solution, in terms of path choices, transport modality, usage of inland terminal and intervention choices. Given a network and a transport demand to satisfy, the other data may have an impact on the decisions to take. Note that in Table 3 the most relevant direct and indirect impacts are reported. 
Table 3: Data impact on decisions

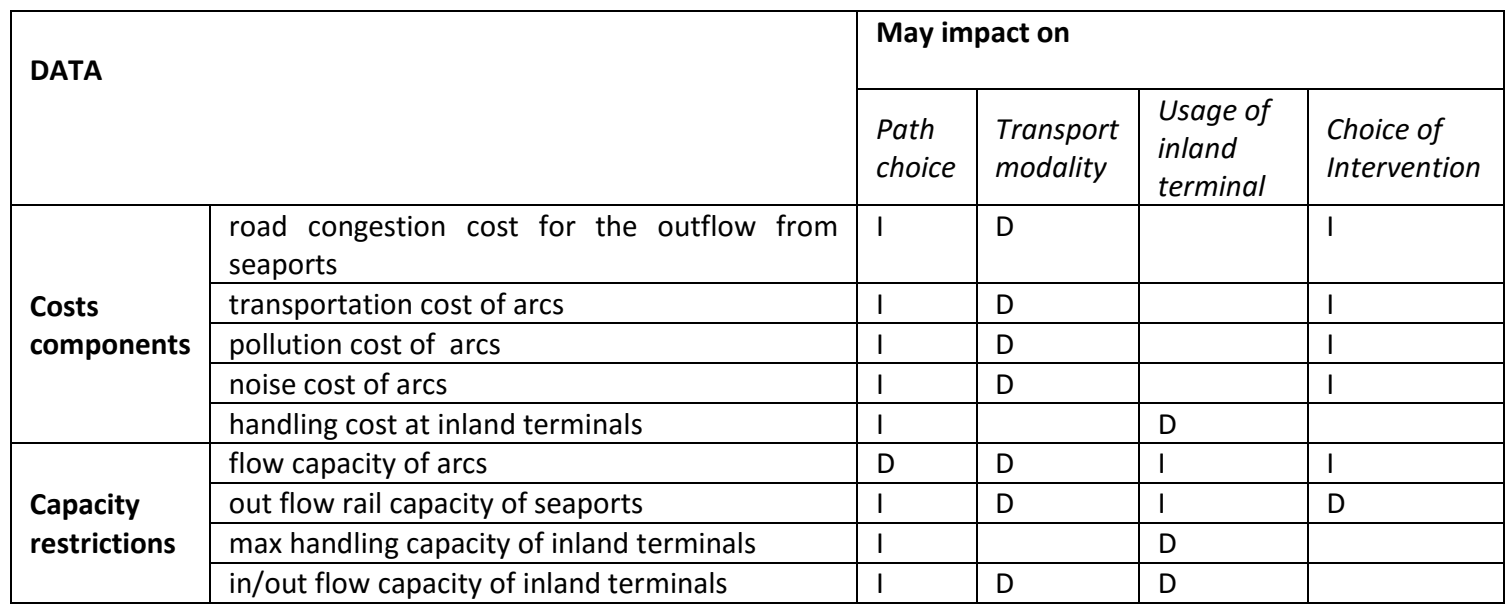

\section{Effects of the planned transformation on the modal split}

The interventions described in Table $2(11,12$ and 13$)$ benefit the network with an increased rail capacity of both the origin nodes (i.e. the ports) and some arcs.

Just to have a parameter to understand how many of the transport demand could be shipped from ports by train, the rail capacity is measured as the ratio between the total rail capacity at the origin nodes and the sum of the o-d demands to satisfy. The current rail capacity of the $\mathrm{CN}$ and ON corresponds to $50 \%$ of the total flows of the network.

Intervention 11 can be realized in two different ways, i.e. trains with 5 wagons more $11(5)$ and with 10 wagons more I1(10); moreover, it is possible to realize different combinations of interventions (i.e. $11(10)+12,11(10)+12+13)$.

Looking at Figure 4 it is possible to note that the current rail capacity $(50 \%)$ can be increased up to $54 \%$ when I1(5) is realized, and reaches the $85.5 \%$ when two interventions are realized, i.e. trains with additional ten wagons and transformation of the rail terminal in one port granting additional ten trains-day. Note that the effects of the interventions in terms of new rail capacity are the same in both the $\mathrm{CN}$ and $\mathrm{ON}$. 
Figure 4: Interventions and rail capacity variation in the network

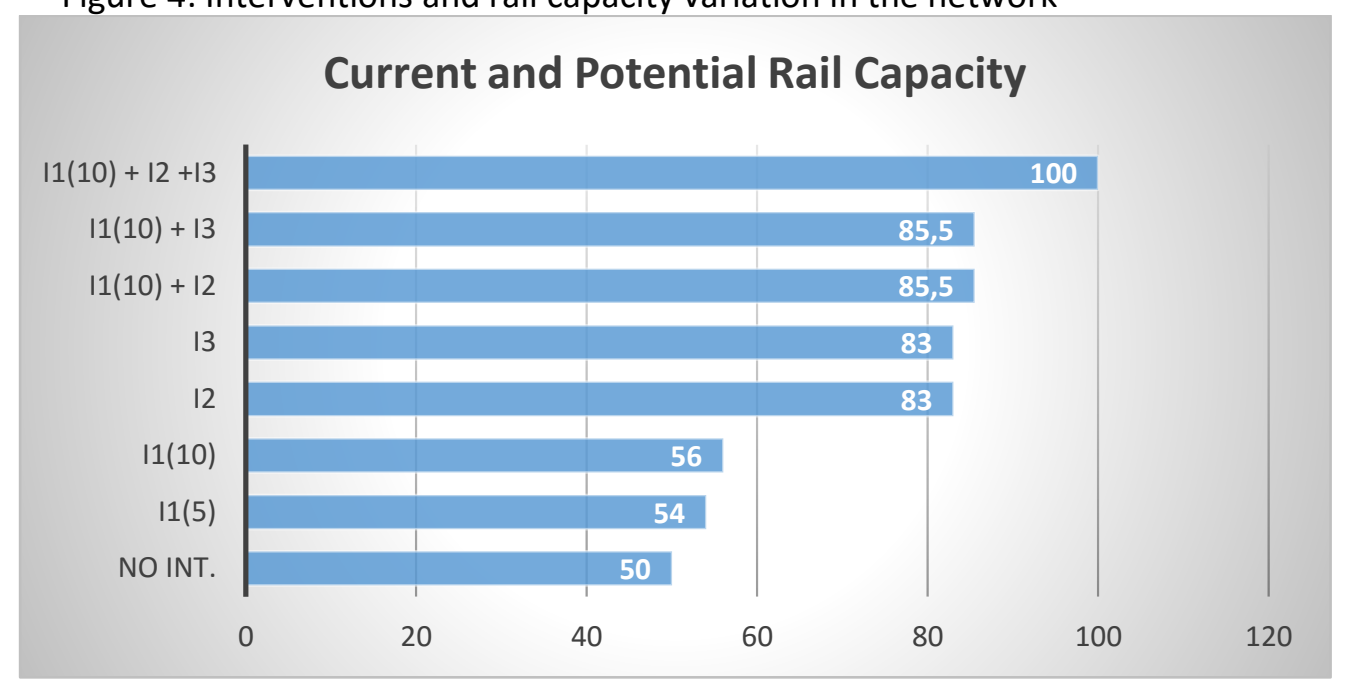

Having a higher rail capacity does not mean to have a higher rail share when shipping goods are in the network. In order to evaluate the effects of the planned interventions on the rail share, we determined through the spreadsheet and compared the optimal flows for the different scenarios showed in Figure 4. In particular, the optimal flows are determined for both the $\mathrm{CN}$ and $\mathrm{ON}$. Note that all the optimal flow problems have been solved through the solver of the spreadsheet twice: including or not the external costs in the total logistic cost to be minimized. The obtained results are reported in the following Figures.

Figure 5 stresses the usage of the potential rail capacity that is here measured in terms of percentage of flow exiting from the origin nodes by rail. Figure 5 reports the results obtained including external costs in the decision making process (i.e. the objective function to be minimized is the sum of transportation, handling and external costs) since, if external costs are not minimized, the percentage of flow leaving the origin nodes (ports) by rail remains fixed to $8.5 \%$ for all scenarios. This means that every type of intervention is not able to increase the rail share without including external costs. Moreover, there is no difference in the used rail capacity at the origin nodes in the $\mathrm{CN}$ and in the $\mathrm{ON}$. 
Figure 5: Rail capacity usages at origin nodes

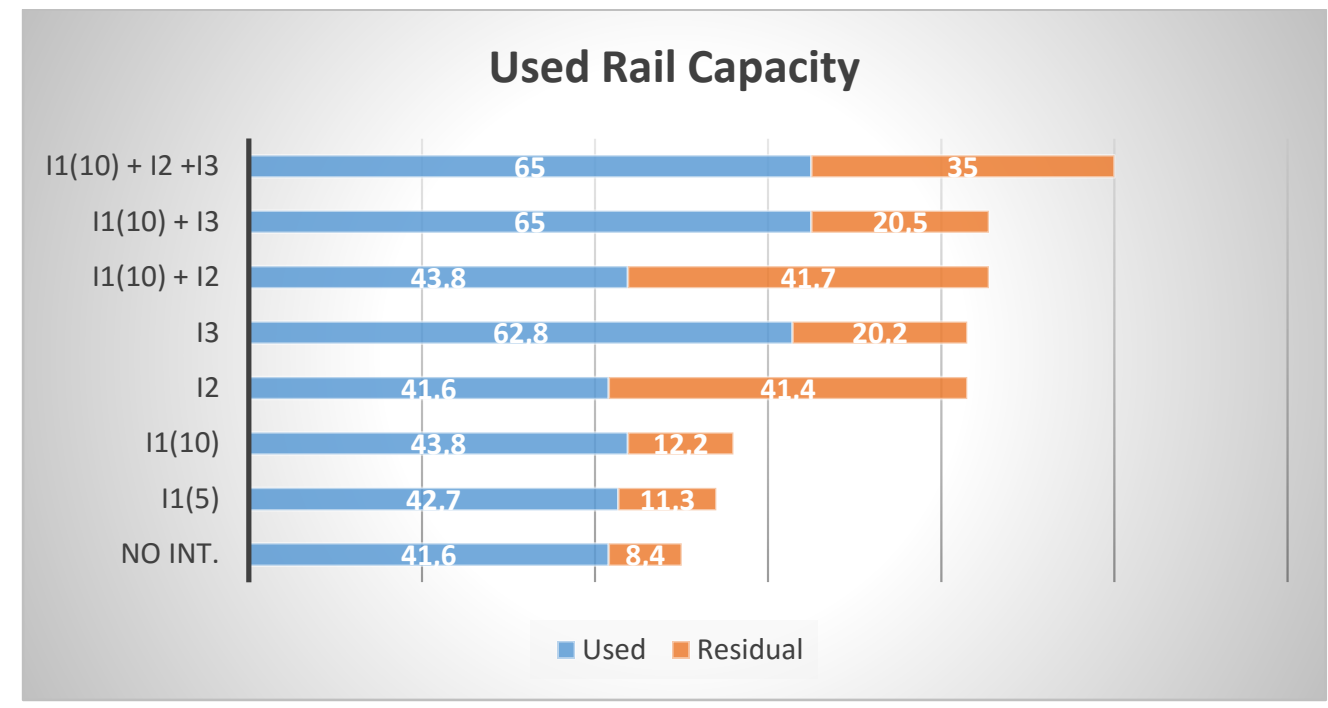

ON differs from $\mathrm{CN}$ for the presence of an inland port. The inland port permits to increase the rail share in the flows reaching destination nodes that is $57.6 \%$ in the network without transformations and reaches $79.9 \%$ as shown in the following Figure 6. In Figure 6, the out-flow from origin nodes (blue) is the total rail share used in the current network (CN), the out-flow from inland ports (orange) is the added rail share in the optimal network (ON). The percentage of out flow from inland ports by rail does not change with the planned transformations: $14.9 \%$ represents the rail capacity of the inland port in the optimal network and this capacity is completely used in all scenarios.

Figure 6: Rail capacity usages in the networks

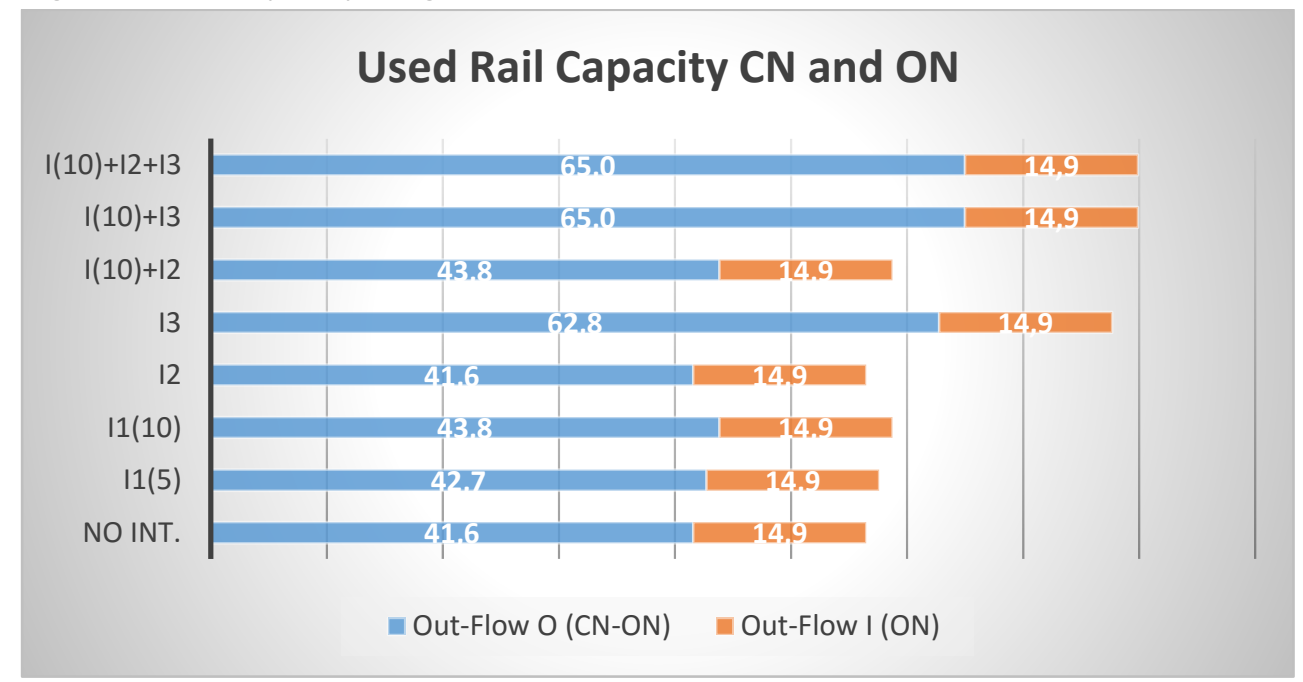

The last analysis regards a comparison of the modal split and the transport costs in the $\mathrm{CN}$ and $\mathrm{ON}$ in two different cases, i.e. with the internalization of external costs and without their internalization. Without the internalization of external costs the rail share in the outflow from the origin nodes is really low (8.5\%), the same for the inflow at destination nodes; the modal split remains the same in the current and in the optimal network as well. 
The internalization of the external costs permits to increase these shares that pass from the $8.5 \%$ to $65 \%$ for the outflow from origin nodes and even reach $79.9 \%$ as inflow at destination nodes in the optimal network with an inland port (that is used to increase the rail mode of transport).

From the previous results it is easy to note that solutions obtained without including external costs in the decision making process are characterized by a very low utilization of the rail. In fact, without the external costs, the optimal flows obtained by the spreadsheet depict a situation quite similar to the real case, also when there is an operative inland port that could facilitate the intermodal transport, anyway it is not effective in balancing the distribution of goods between the rail and road modes. Instead, the internalization of the external costs contributes to rationalize the transport flows.

Figure 7: Total costs of the system

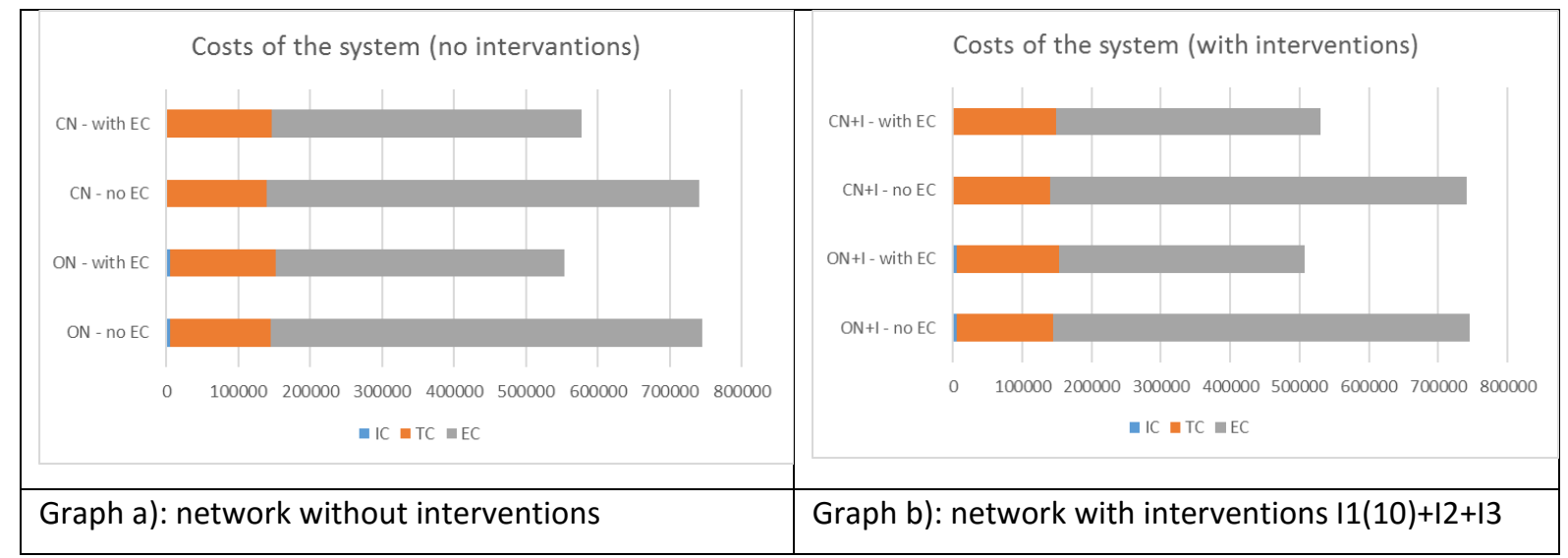

Figure 7 shows the total costs of the system obtained as sum of the transportation costs, inland costs and external costs. The difference regarding the external costs is that in one case they are included in the decision process (with EC) and in the opposite case they are excluded by this process (no EC); it is important to note that the external costs are generated in any case and when they are not included in the decision making process, no one pay attention to them and they grow considerably (representing more than $80 \%$ of the total costs). The $\mathrm{CN}$ and $\mathrm{ON}$ are compared in two cases: without interventions in the network [graph a] and with the interventions $11(10)+12+13$ in the network [graph b].

In graph a) the costs of the system result lower when the external costs are included in the decision making process of about $24 \%$ (i.e. $\mathrm{CN}$ - with $\mathrm{EC}$, ON - with EC). The same data in the networks with the planned intervention (graph b)) is higher: the saving is about $30 \%$.

The best solution in terms of system costs is ON-with EC with interventions having a total network cost partitioned as follows: inland costs $(0.9 \%)$, transportation costs $(29.3 \%)$ and external costs (69.8\%). In particular, the external costs are given by $41 \%$ pollution and noise for road transport, $26 \%$ pollution and noise for rail transport and $3 \%$ for congestion at the seaports. Note that this solution is not too much affected by variations in the road transport costs (due, for instance, to the rise of oil cost). In fact, the modal split and the paths used remain the same since the internalization of the external costs in the decision process has brought solutions with a saturation of the paths' rail capacity. Instead, when external costs are not included in the decision process, a low increase in the road transport costs is sufficient to obtain solution with higher rail share (e.g. rail share passes from $8.5 \%$ to $27.1 \%$ when the road cost increases of $5 \%$ ). 


\section{Policy indications}

Current analysis showed how the internalisation of external costs might support a more sustainable modal split while the already planned infrastructure investments - even if mostly concentrated on railways, i.e. the most environmental friendly transport mode - could not generate any steady improvement in comparison to the current situation. In fact, only a policy intervention aiming at internalizing the social costs mostly generated by the road transport could effectively affect the outcome of the investment policy. On this regard, it is important the introduction of the Ferrobonus policy (RAM, 2016) as a possible tool to incentivize the shift from road to rail freight transport. This policy tool has been promoted by the Italian government and recently approved by the EU Commission, supporting it as an incentive not in contrast with the European competition rule. This monetary contribution should incentivize the shift from road to rail. Unfortunately, none of these incentives is linked to the extra-costs generated by the road transport per $\mathrm{km}$ (and then proportional to the savings in terms of externalities) but it is calculated as a monetary transfer guaranteed in relation to the possibility of organizing a full train able to substitute a truck service. Thus, Ferrobonus appears as an excellent starting point for the promotion of the rail freight transport but it doesn't guarantee the necessary transfer of costs/benefits from the user of a transport mode to another.

Despite this issue, the current research shows how the organization of this cross-transfer between rail and road could represent a cornerstone in the current transport planning activity, also generating enough demand to already satisfy the growing rail transport capacity that - without any intervention - would be wasted.

For instance, since the generated externalities linked to pollution double (or grow even more) when road transport is preferred to rail, a taxation aiming at balancing this difference would strongly impact on modal split of the freight cargo, optimizing current planned and funded transport investments. Eventually, it is worth to notice that the outcome shows how this incentive would affect also the overall usage of the current rail network: currently the infrastructure limitation of the rail network affects the possibility to organize full trains from the ports to the final destinations. Furthermore, the already planned new links connecting the port of Genoa to main hinterland destinations, will allow the operators to organize longer trains (maximum capacity of 500 meters), potentially increasing the train share of $30 \%$ in comparison to the calculated optimal scenario.

Another interesting result of this work is the role of inland ports as nodes that interconnect rail and road transport systems thus contributing to the development of intermodal supply chains, especially in cases as the one we investigated where some rail links could hardly be chosen by freight due to their limitation. Moreover, it is worth noticing that in other regional framework in which cargo aggregation procedure might be more efficient (e.g. larger countries or polarized port regions) the higher quality of the rail service in respect to the current Italian situation might guarantee an easier train organization (e.g. higher loading factor, higher frequency) improving the proposed solution. Thus, even if the current Italian rail market organization and average distance are not allowing an increasing port competitiveness, the possibility to make rail services more convenient could incentivize more competitive solutions, potentially increasing the hinterland served by Northern Italian ports.

In fact, in our case the sole insertion of either external costs or infrastructure improvements does not increase the chances of organizing this kind of rail trips. The proposed solution achieves this goal also increasing the possibility to exploit main advantages of the rail transport that is normally competitive for long distances. This fact seems not guaranteed by the scenarios in which only one of the possible 
alternative transformations is applied but it could be met in regional framework experiencing, for instance bigger distances between the port and the main markets. 


\section{References}

Al Enezy O., Van Hassel E., Sys C., Vanelslander T. (2016). Design of a cost calculation instrument for the inland navigation sector, proceedings of the 2016 WCTR Conference, Shanghai

Ambrosino D., Ferrari C., Sciomachen A., Tei A. (2016). Intermodal nodes and external costs: Rethinking the current network organization, Research in Transportation Business \& Management, 19, pp. 106-117.

Ambrosino D., Sciomachen A. (2016). A capacitated hub location problem in freight logistics multimodal networks. Optimization Letters, 10, pp 875-901.

Ambrosino D., Sciomachen A. (2014). Location of mid-range dry ports in multimodal logistic networks, Procedia - Social and Behavioral Sciences, 1, 108, pp. 118-128.

Arnold P., Peeters D., and Thomas I. (2004). Modelling a rail/road intermodal transportation system, Transportation Research Part E, 40, 3, pp. 255-270.

Assoporti (2016). www.assoporti.it, online statistics.

Autostrade per I'Italia (2015). www.autostrade.it, online statistics.

Baumgartner J.P., (2001). Price and costs in the railway sector, Litep, Ecole Polytechnique Federal de Lausanne.

Bottasso A., Conti M., Ferrari C., Tei A. (2014). Ports and regional development: a spatial analysis on a panel of European regions, Transportation Research Part A, 65, pp. 44-55.

Consulta Nazionale per l'Autotrasporto e la Logistica (2011). National Logistics Plan 2011-2020. Rome.

De Martino, M., Erricchello, L., Marasco, A., and Morvillo, A. (2013). Logistics Innovation in Seaports: An inter-organizational perspective, Research in Transportation Business \& Management, 8, pp. 123133.

Eng-Larsson F., Kohn C. (2012). Modal Shift for Greener Logistics - the Shipper's Perspective, International Journal of Physical Distribution \& Logistics Management, 42, pp. 36-59.

European Environment Agency - EEA (2010). Towards a resource-efficient transport system TERM 2009: indicators tracking transport and environment in the European Union, EEA report, n.2, Bruxelles.

European Environment Agency - EEA (2015). www.eea.europa.eu, online statistics.

Ferrari C., Parola F., Gattorna E. (2011). Measuring the Quality of Port Hinterland Accessibility: The Ligurian Case, Transport Policy, 18, 2, pp. 382-391.

Ferrari C., Tei A. (2012). Emission savings through a re-scheduling of maritime services: possible implications for the Mediterranean ports. Economics and Policy of Energy and the Environment, 2, pp. 113-130.

Grosso M. (2011). The Competitiveness of Intermodal Transport: Applications on European Corridors, Phd Thesis, Genoa-Antwerp.

lannone F. (2012). The private and social cost efficiency of port hinterland container distribution through a regional logistics system, Transportation Research PartA, 46, 9, pp. 1424-1448.

Italian Ministry of Transport (2015). Albo degli autotrasportatori.

Lindstad H., Asbjørnslett B., Strømman A. (2016). Opportunities for increased profit and reduced cost and emissions by service differentiation within container liner shipping, Maritime Policy \& Management, 43, pp. 280-294.

Janic M. (2007). Modelling the full costs of an intermodal and road freight transport network, Transportation Research Part D, 12, 1, pp. 33-44. 
Lakshmanan T., Nijkamp P., Rietveld P., and Verhoef E.T. (2001). Benefits and costs of transport: Classification, methodologies and policies, Papers in Regional Science , 80, 2 , pp 139-164.

Maibach M., Schreyer C., Sutter D., van Essen H.P., Boon B.H., Smokers R., Schroten A., Doll C., Pawlowska B., Bak M. (2008). Handbook on estimation of external costs in the transport sector, IMPACT Project, Delft

Meersman H., Van de Voorde E., Winkelmans W. (1998). Transport Modes and Systems. Vol. 1, Amsterdam, Pergamon.

Meersman H., Van de Voorde, E., Vanelslander T. (2009). Future Challenges for Port and Shipping Sector, Informa, London.

Mostert M., Limbourg S. (2016). External Costs as Competitiveness Factors for Freight Transport A State of the Art, Transport Reviews, 36, pp. 692-712.

Mostert M., Caris A., Limbourg S. (2017). Road and intermodal transport performance: the impact of operational costs and air pollution external costs, Research in Transportation Business and Management, 23, pp. 75-85.

Notteboom T., Rodrigue J.P. (2008). Containerization, box logistics and global supply chains: the integration of ports and liner shipping networks, Maritime Economics and Logistic, 10, pp. 152-174.

Parola F., Ferrari C., Musso E., Satta G., Tei A. (2016). Dealing with multi-scalar embeddedness and institutional divergence: evidence from the renovation of Italian port governance, Research in Transportation Business \& Management, forthcoming.

Pigou, A.C., (1932), The Economics of Welfare. MacMillan, 4th edition, London

RAM - Rete Autostrade Mediterranee (2016). http://www.ramspa.it/cosafacciamo/incentivi/nuovo-ferrobonus.

Regione Liguria (2010). Regional Logistics Plan, Genoa.

Rete Ferroviaria Italiana -RFI (2016). www.rfi.it, online documentations

Sambracos E., Maniati M. (2012). Competitiveness between short sea shipping and road freight transport in mainland port connections; the case of two Greek ports, Maritime Policy \& Management, 39, pp. 321-337.

Schwarze S., Voss S. (2015). Interaction of maritime shipping and hinterland traffic using a two-level hierarchical transport network, International Journal of Logistics Research and Applications, 18, pp. 276-290.

Tongzon J.L. (2009). Port choice and freight forwarders, Transportation Research Part E, 45, pp. 186-195.

Van Den Berg R., De Langen P.W. (2011). Hinterland Strategies of Port Authorities: A Case Study of the Port of Barcelona, Research in Transportation Economics, 3, pp. 6-14.

Van der Horst M., van der Lugt L. (2011). Coordination mechanisms in improving hinterland accessibility: empirical analysis in the port of Rotterdam, Maritime Policy \& Management, 38, pp. 415435.

Vermeiren V., Macharis C. (2016). Intermodal land transportation systems and port choice, an analysis of stated choices among shippers in the Rhine-Scheldt delta, Maritime Policy \& Management, 43, pp. 992-1004.

Yang J., Luo M., Ji A. (2016). Analyzing the spatial-temporal evolution of a gateway's hinterland: A case study of Shanghai, China, Transportation Research Part E. 95, pp. 355-367. 